\title{
Market Analysis about Successful Animation Characters and The Important Elements Point of Create Animated Characters

\author{
Changrong Peng
}

Department of Animation school, Hebei Institute of Fine Art ,ShiJiaZhuang HeBei, 050700, China

Keywords: Animation; Animation design; Animation industry; Innovation consciousness

\begin{abstract}
In the era of creative background, the consciousness of all countries in the world behind the animation industry contains a huge economic benefits, anime game market competition is fierce. Animation is a visual strong cultural industry as a whole, animation image is its soul. A successful animated characters, the producers and the audience must have the best visual transmission capacity. At the present stage abroad and the situation of China's animation industry, analysis of China's advantages and disadvantages of animation design. To domestic animation modeling brand shaping direction and animation industry development direction of rationalization proposal is put forward.
\end{abstract}

\section{Innovative Consciousness of the Contemporary Chinese Animation Modeling}

Aesthetes Benedetto Croce once noted, "artists of all skills, is to create the cause of readers aesthetic to create stimuli." [1] Animation role modeling is a picture of a creative element, it provides the same lens, also should create can cause the audience aesthetic to create images of the image. Therefore, how to create this stimulus, it needs to creators hold good creative elements. The formation of innovative need high level and strong professional and cooperation of animation talents.

Creativity is a kind of creative thinking activity, only novel creative picture will have a strong visual result, will attract the attention of the audience. Due to the animation market is booming, the animation industry in China in recent years is in constant development. Related animation professional higher education and vocational education were booming up also. But at present, there are few on the market of the outstanding works and especially the originality and artistry strong animation works very little. Despite the animation technology and market factors, such as but fundamentally, is still the animation modeling side there is a problem. The development of Chinese animation which restrict the development of the Chinese original cartoon is the most key factors: imitation is too much, that force is not enough, insufficient funds, the investment is not enough, marketing, brand influence is not enough, supporting policy is not enough, and so on.

The respect is designed in the shape of cartoon characters, the big heaven "which Cha make sea" gobbledygook, tan and other traditional cartoons borrowed from Chinese ancient temple murals shape; "The south guo", "children's fire, combined with the energetic style of Han dynasty stone and brick; "Proud generals", "the doctor and the emperor", by assignment of Peking Opera to distinct personality characters. In terms of cartoon character design, the traditional Chinese animation also has a lot of success. , for example, naughty monkeys in the monkey hill ", "long" in kind and beautiful long hair younger sister, the small carp jump dragon, brave lovely small carp, the story of any lift in witty avanty.

Cartoon image of the design about the publication of the anime products, showing on the market, also related to the derivatives market sale, with Chinese culture in order to make animation product to gain a larger share in the market, we must be poured more effort in this condition.

\section{The Standardization of Contemporary Chinese Animation Modeling}

The film and television animation is a system engineering, it needs all kinds of talents work together to complete. In the middle, the standardization of a visual animation image design will play a very important role.

Because our country animation technology talents and animation art talent too separation, cause 
in the film and television animation produced the phenomenon of $\backslash$ "each dry, irrelevant $\backslash "$. Some animation role in production process of standard execution, resulting in a cartoon character who is incomplete, even appear in the image is inconsistent problems in each scenario. Animation industry in China is a big famous comic \"dream man〉", is the Wuhan cartoonist Yao Fei street. After decided to animate, contracted by the twelve animation production companies. After two years of production in the process of synthesis, found the role modeling separation, role in a dozen of the finished product with twelve kinds of shape. The same embarrassment in the domestic animation ।"batman Zhang Gal" again[2].

On April 20, 2004, the state administration of radio, film and television in the several opinions about development of film and television animation industry in China, to support and encourage the domestic film and television animation industry and the overseas animation industry widely beneficial cooperation. Hope that through cooperation with foreign animators, learning, learning, absorbing foreign system of image creation pattern and standardized execution mode, to improve the standardized question of the animation image in animation industry of our country.

\section{Cartoon Stars-virtual Image of Brand Spokesperson}

Copyright, right of image is the lifeline of animation industry, it is not only basic throughout all of the industrial chain link, also for those links profit obtained legal protection. In theory, a cultural works a born naturally have copyright or image rights, but only with image copyright, rights and interests is not enough. Because if the cultural goods can't form a brand, no brand in the market, so it is difficult to translate into significant economic value. Brand is a symbol system has obvious competitive advantage, the elements of the product for the integrated embodiment and as the symbol of the product, it can contribute to rapid communication with consumers, make the enterprise benefit has been achieved. The formation of the brand is very difficult, it requires good creativity and vigorously publicity, consumes a lot of manpower and financial resources. Therefore, once formed, will be strictly protected, and seize the opportunity to implement the brand expansion, only in this way, can create a tangible economic value.

Relative to other cultural industries, brand of animation industry also has the decisive significance. Walt Disney is often said that Disney's all started with a mouse, this is very vividly illustrate the importance of the brand. So far, the "old" Mickey Mouse is still in a lot of profit for Disney company. For animation industry, only to make a "golden signboard" outstanding creative, can really get huge economic power.

Animation brand star is the virtual animation company spokesperson. Stand out its advantages: first, it can in a unique image to attract more attention, and can be largely: get rid of the defects of reality star typed. Second, the cartoon stars are not afraid of aging, can stay young forever, lovely image, long-term for the animation enterprise. Third, the cartoon stars artistic life, but not real life. Thus, once it is created as cartoon animation enterprise intangible assets, long-term have animation enterprise does not need to pay for these cartoon star. On these don't pay, not afraid of aging, the image of the unique virtual spokesperson, represented by the Walt Disney company a number of animation companies to become "longevity enterprise" and the industry's giants. [3]

In the animation industry developed countries, before the animation will be demonstrated fully the role image. The Walt Disney company has special the role of the designer, in addition, the creative execution department also want the role image repeatedly discussed and modifying, examining whether it can meet the needs of the derivatives market. In Japan and South Korea, the project company, making committee also attaches great importance to character set. Especially production committee, including a lot of moment derivatives developers. SBS in South Korea, for example, an animation production company in the project, its production committee members include not only Japan's top (sunrise) company, animation company, also including the toy image licensees. At the beginning of the animation, the planning and production committee members will be to a premade character animation image, to ensure that these animated star after entering the derivatives market to create a steady stream of wealth.

By authorization of the image, animation, stars not only more widely entered people's lives, but 
also created a huge wealth for the society. Now, these animation derivatives have been published on Forbes list of the "virtual image", such as Mickey Mouse, winnie the pooh, Pikachu, etc.

Based on the comic in Japan, usually in good shooting film and television animation, and then animated stars as models to build derivatives. After a long period of industry, the traditional operation mode has been widely used. And on this basis, also produced a variety of other operations, such as "Pikachu model" : by the game's image into the derivatives of the image and animation image. As early as 1996, Pikachu also is just a cartoon image of the nintendo games, according to Lin's production department to realize the image of the business potential, so and nintendo company signed a contract, and registered the exclusive ownership of Pikachu image. This vision brought according to Lin club lucre. U.S. financial magazine Forbes list of the "virtual image", published in 2003, according to Pikachu is worth $\$ 825$ million. In September 1998, the pocket monster (namely the Pikachu) when the first animated film premiere in the us hit a $\$ 10.1$ million at the first cartoon box office record. In this sensationalism, the film's CD listed on the first day of sales reached 1 million copies. "And" pocket monster cartoons since its release in April 1999, soon breached 2.4 billion pieces, easily more than the record sales of 1.6 billion Japanese.

These forms are flexibly used alternately, has formed a cartoon, animation and game centered "industry network". While successful cartoon image is to promote the "net" in every key step of market profits industry. Now, Japan, the island country people much less and limited resources have got from the development of animation industry huge returns.

\section{Brand Status and Existing Problems of Our Country's Animation Image}

Animation is a visual strong cultural industry as a whole, animation image is its soul, animation technology is the blood, is connected to the art and the essential condition of technical factors, create perfect animation. So, choose image in animation modeling and related factors can not be ignored, at the same time. We argued for animation image in the native culture should be the high cultural taste, national style and unique modeling form, and adapted to the animation art culture resources. As a new generation of animation designer, should notice to examine the modeling of the most expressive language in Chinese art. How to put these rich image specific and personalized and integrated refining, still need a process of re-creation. In five, $60 \mathrm{~s}$, China has a large number of excellent animation, traced back, from WJH brothers create a Chinese animation history, has been 70 years, however, emphasis on animation art forms and materials, enabled us to ignore the animation excavation and shaping of the brand image.

First, this ring disconnect from anime products to derivatives, fault in severe cases. Because our country animation original level is not high, the lack of influential domestic cartoon star, so, can enter the link of derivatives of domestic animation image is very limited, plus the lack of mature and orderly derivatives authorization mechanism in our country, so this ring disconnect from anime products to derivatives, fault in severe cases.

Second, China's animation derivative product less well-known brands, industry scale small, the overall strength is weak, in the face of the impact of foreign animation derivative products obviously in a weak position. Although Hunan, Shanghai, Guangdong and other places have opened authorization, and business operation activities of the animation derivative products, anime products authorization mechanisms have been established, however, overall, less well-known brands, animation derivatives industry in China small scale, weak overall strength.

Third, the authorization system chaos, lack of management. The sunchime cartoon group authorized production blue cat series of children's products since the end of 2001, three years is quickly produced dozens of professional companies, more than 6000 kinds of products. Only in the food and beverage industry, there are four "blue cat". By the end of 2003, blue cat agent has more than 180, stores more than 2600. However, the rapid development also brings blind expansion, unsound management. The sunchime cartoon group and the coordination between the authorized enterprises, thousands of derivatives regulatory problems, the quality of the large number of new signing dealers management problems plagued the sunchime group.

Fourth, the protection of domestic animation brand is not strong enough. This is mainly 
embodied in two aspects: first, to create animation brand at the same time the lack of relevant legal consciousness, that all be lost to the cartoon the legal rights of the brand. Second, in our country, unauthorized illegal processing of animation derivative products are common, and the ministry of commerce and industry crackdown is not enough. For example, the Beijing Olympic Games mascots fuwa just released soon, will appear on the market a lot of illegal production of fuwa toys; Pleasant goat is randomly generic image toys and so on.

From domestic these obvious problems we realize the importance of brand, we need to carry out brand operation state reference and learning. In domestic good policy guidance and help, gradually consummates our country animation industry system, support domestic cartoon image of the brand, strengthen the protection of domestic animation brand, cultivating of art and technology together in one comprehensive animation design talent, formed a mastering many skills while specializing in, diversity of knowledge structure and ability to work in a strong market awareness, high specialization of film and television animation production team. This is also the Chinese animation industry gradually improve, strategy of regrouped, create brilliant.

Animation is highly assumption, its main characteristic is not the pursuit of image lifelike, and is embodied by its peculiar modeling way to convey some ideas and aesthetic. Animation role modeling is using these ways, through the film and television techniques to use to display the role of forms, including character portraits, expressions, clothes, movements and so on conventional factors. And it has been the success comes from a good animation character design. So how to do animation character design, is we have to expand the next topic.

The Basic Concept of Animation Role Modeling and Performance. Animation role is to be given life in animation works activities, in the form of various performance main body, which not only contain characters, sometimes including animals, plants, and even a fantasy of genie elves and an inanimate object, etc. Works in animation role modeling of unexpectedly is the performer, like the actor to express the plot, thoughts, to convey creators is expected Ding Huan, dominated the development of the plot and the establishment of the style. Successful animation role model not only has the unique artistic charm in the artistic image, meet the audience's aesthetic requirements, get the audience's hot but with love, and can reflect its value in the business class, and has huge market profits, there is a follow-up of business development space. Such as, the Disney classical animation role modeling - Mickey Mouse and friends, it is a most successful development of the global animation, animation image of the most representative.

By artificial characters that comes to life in a particular environment to rely on, the particular environment is the story. Animation role modeling is not isolated, static and inanimate, she needs to be on the basis of the plot system for design. Character is the essence of promoting the story occurrence and development with the core elements of the animation designer can understand the role of story character modeling is the key to the success of character design, so the command of the character is the primary task of design.

Successful character with the teahouse has a distinct personality characteristics, and with a certain universality. Because according to the story and assume that out, the role of its inherent natural (image. Physiology and psychology, etc.) [4]and outer social (geographical environment, historical and social background, etc.) there are differences, thus causing the unique role modeling in appearance, form, costumes and performance, dynamic, behavior in the design of the different performance, in the end by the winding complex plot progress in keeping up its integrity and penetrability, can form unified and clear behavior, deepen the audience to grasp and understanding of the role.

Role of Static Modeling and Dynamic Modeling of the Performance. From the point of view of film and television art, animation role modeling can be static modeling and dynamic modeling of flavor.

The Static Shape. Animated characters of static that modeling as well as painting, sculpture, photography requires a static beauty, through the role to pause or picture frames of the moment, to show the role of the overall image, local, facial expressions, traits of character, etc. In the static model, form design, costume props. Role of the virtual image is modeling designer out visual image, 
in addition to meet the development of the plot, also need on the performance of the aesthetic, manifests the animation role modeling the special aesthetic taste.

(1)The Manifestation of the Head Shape. The shape of the head can reflect the character in age, character and expression, is the most important part, different from other roles is to convey character emotions, perception of the key parts of the role of emotions and psychological state, the audience to the attention of a character from the head start. Modeling of the head design to reflect the characteristics of the character signature - looks and expressions. Thanks to modern animation film language is widely used in the film, make its transformation between different Jingbie use is unusually rich. Close shot, close-up and play close-up role needs to be above the chest, and even the whole detailed clear details of the head. Camera closer, facial features and expressions of the amplifier, taste can be a strong visual impact effect, strengthening the expressive force of the film, reflect exquisite and the role of the real inner activities. Exam-oriented technique application, make modern animation film not continuously improve to head modeling design requirement, more precise and detailed.

(2)Role Modeling Design Form. Form of animation role modeling design is modeling that cannot be ignored in the process of link, including the role of body height ratio and different angles of surface figure. Animated characters height ratio generally based on head length measured, "in ancient Chinese painting had driven a human body proportion of early 'vertical five, seven, sit three and a half." In the realism of animated usually based on the structure of the normal proportion, sometimes slightly exaggerated; And comic style role modeling height ratio is in accordance with the normal structure than to have a purpose of exaggeration and deformation on the form, common is three to five heads, the proportion of the arbitrary nature and freedom. Turn the role of surface figure refers to the various decent, point of view, including front, side and back, look up, down, top view, etc. Modern cartoon film for reference in the expression of multiple points of view, using role brick surface to strengthen the role of stereo feeling, rich footage visual expression, as much as possible to the audience from any Angle to appreciate and understand the role, enhance the appeal of the picture and visual impact.

(3)Clothing and the Performance of the Color in the Role Modeling. Role in shaping the image of the process, in addition to the role of limbs, facial features, facial expressions, and other necessary appearance design, have important influence factors for shaping characters, and the collocation of clothing. Good dress collocation can often in the first time to reveal the role of background and personality characteristics of image, thus saving a lot of time and energy in language and action link to the larger operations such as the difficulty for these information, can make the audience in the shortest possible time get the most intuitive role of rich information. Clothing design and animation role modeling is an integral part of the static, including clothing, pants, shoes, hats, jewelry, and other accessories, and so on. The set of dress reflects the customs of each country and culture, is the epitome of human material civilization; And directly reflects the character's personality, is a reflection of human ideology and the emotion world. Pink is the color of the most popular with women. Wear pink clothes often the role of personality gentleness, the idea is exquisite, compassionate, caring others meticulously, but weakness is their character weakness. Role animation modeling, therefore, the designers in the design of dress, the color of the dress is very important.

The Dynamic Shape. Animated characters of dynamic modeling is usually reflected in the conflict on the role of the movement and dynamic performance. Should be like static modeling design, based on the subject of the film, drama conflict, styles and forms of different shape, and give full play to the characteristics of the animation technique of expression. Compared to animation and live-action film and television works, to beautify the effect of the actions and gestures. Due to the height of the animation assumption, in the imagination to reality can't appear under the domination of the movements and scenes. Animation roles in action in the form of painting as a performance measure, one by the designer to draw a complete set of movements of micro-motion individually, although it is static, but it is gradually changing. Via the way one photograph or scan, and then played to a certain speed, forming a coherent action again. Dynamic 
and action of the human body is by the movement of the bones and muscles. Person or animal skeletal muscle structure is complex, the designers in dynamic modeling, need to find the key anchor point of the joints - head, chest, pelvis and limbs on the elbow, knee, they determine the role of the activity rule of movement and scope, and have the effect of lead trunk twisting, coordinate balance. Role modeling of dynamic performance to meet the body's natural movement rule, at the same time in the grasp and balance of human body joint, the freedom of dynamic design. Role of dynamic modeling besides can directly reflect the character's actions, it could indirectly performance animation character's psychological activity and personality traits. When my characters feeling angry, in addition to facial expression, on the dynamic behavior sometimes use clenched fist, catch hair, go to realistic exaggerated dynamic performance. Show different personality character (extroverted or introverted, proud or humble, dense or clever, etc.), on the dynamic modeling also is not the same. Cartoon, for example, the dynamic modeling of the crayon small new, foolish is slow to show its stolid personality, and smart and lively small new form bright contrast.

Character Modeling Style. In the pre-production stage of animation, need according to the script to confirm the art style of the film. Modern cartoon faces audience increasingly diversified, confined to children by the past a single group gradually shift to teenagers, adults and even older viewers, which makes the animation presents diversified situation on the subject. From the traditional preaching words, humorous, detective gradually extended to the suspense, science fiction, love adventure novel drama theme, such as animation script story determines the role modeling style, has changed the integral style of the cartoon. Modern animation role modeling from the realistic, cartoons and art style.

Realism Role Modeling. Realism role modeling on the expression of body shape usually follow the reality of living organisms, weaken the modeling of the designer's personal subjective emotional factors. With their specific populations, bones., scale, on the basis of age, characteristics, role model, on the basis of summarizing and refining of represented by animation unique assumption. Realism of the animation work is usually a comic style closer to the real nature, in its performance close to the distance between character and audience, strong affinity, easy to resonate. From the point of view of global animation role modeling style, different countries and regions there are certain differences in the design performance. It not only related to the regional designer painting style habits, also between the region and the special spirit of national culture, historical background and long-term accumulation of the aesthetic habits and people's overall qualities, such as personality factors have a direct relationship. Modern animation modeling of realism is mainly represented by Europe and the United States and the Japanese animation, each has its typical. Japanese animation role modeling style characteristic extremely sharp, line is rigorous, strong sense of form, modeling detail, meticulous, numerous and not random; Apparel modeling elegant, gorgeous, the whole role modeling aesthetic pursuit, pay attention to the form of commercial sense. In addition to according to the proportion of normal height, facial features weakened the modeling of nose and mouth and exaggerate the eyes. Modeling is exquisite, delicate, facial ratio is larger, light feeling strong. And European and American realism pays attention to the modeling of light and shadow, volume, emphasize on the role of modeling is strict, the body structure is rigorous. Bones and muscles features accurate and clear, the male and female character characteristic, has the extremely lifelike, such as Europe and the United States animation characters like superman, cat woman, classic. 'Chinese comic art modeling has a strong realistic style, the role of the form and content reflect the cultural characteristics in our country, with rich Chinese painting style, realistic strong characters, rigorous, vivid shape; On the painting performance, the performance of Chinese painting elements and print black and white effect, enhances the artistic appeal of the picture. The animation art creation in China at the present stage, if can draw lessons from the performance of the comic art style, is the nationalization of Chinese animation process a positive role in promoting.

Comic Style Role Modeling Exaggerated Sexual Performance. Comic style modeling exaggerated artistic effect, the emphasis is on performance including role form structure and deformation of exaggerated facial expressions. Comic role action design are derived from the reality 
on the basis of reprocessing, plot, character and other factors by the designer of the understanding and elaboration of, finally from the real life of modeling, role modeling concise, generalization, pure. Q version of the role modeling is a Japanese cartoon style peculiar form, usually along with the development of the plot, characters, mood changes, than from normal head body mutated into two or three head body height, form the head and body is highly uneven contrast, the audience in incongruous feeling leave deep impression. [5] Q version of the role model's main aim is to create a relaxed and harmonious funny story atmosphere, breaking the original role to the audience brings a sense of tension, serious, show dramatic role heart side, enhance the aesthetic appeal of characters, the connotation of the story diversity, highlighted the assumption of animation and entertainment. European and American comic style design succinct modeling, normally to people or animals with the geometry, to generalize in exaggeration and sarcastic expression, proportion to the body, body structure deformation processing, such as Disney's animation role modeling, by applying the method of circle and arc formed his unique painting techniques, directly affect the whole Europe and comic style character modeling design in the field of animation.

The Characteristics of Artistic Style Role Modeling and Performance. Artistic style of animation modeling is usually in order to highlight the nationalization, the traditional style. Artistic style of animation in China, the artistic forms, not stick to one pattern. WJH brothers in China the first animated feature film "princess iron fan" sun Wukong in the Beijing Opera actor, the princess of the ancient Chinese woman look; Rich opera pattern and the effect of the murals of ancient Chinese and claboratestyle "proud generals"; Peking Opera mask design elements and decorative effect for reference of "the heaven", Nezha conquers make the sea; Buddhist painting style, fusion of dunhuang mural art in the form of animation "nine colored deer"; Chinese animation art wonderful work - wash cartoon "little tadpole looking for mom", "reed pipe", "the deer's bell" and "landscape" and so on, the use of ink and water rendering, shades of ink and the actual situation of effect, the forms of Chinese ink and wash is given priority to with freehand brushwork, exquisite calligraphic style technique, accurate vividly embodies the Chinese traditional aesthetic essence and the artistic style of the plain; And JianZhiPian, origami pieces and puppet film, etc., are unique to China animation art style. Today, this kind of animation style still has huge potential of creation and aesthetic temperament and interest, is a unique artistic style of animation.

In addition, there is a part of the art style of animation role modeling pursuit, the performance of the alternative, they draw lessons from different types of painting art style in the world, including cubism, surrealism, etc. Such works continuously the pursuit of innovation and exploration in painting style, to abandon the commercial animation role modeling of stylized - to meet the demand of the public aesthetic and shaping the role of the beautiful, lovely, beautiful, and emphasizes the experimental and artistic quality, from the traditional performance model, fuzzy, the weakening roles conventional modeling characteristics. Such cartoons often length is not long, usually within 20 minutes, usually by artists for independent producers, in order to show the author's subjective consciousness. As to oil painting as a form of Russian art animation works the old man and the sea; Using the sand thick degree, pervious to light of light and shade effect on light box polish art animation works "swan"; Using physical modeling as a character animation art animation works, and so on. [6] Besides, some animation role modeling extremely abstract art, can be a line, a circle, or difficult to distinguish, with distinct individual character color, such as New Zealand art animation works "three $\mathrm{ZuWu}$ " in the form of abstract shape, unique painting shows the emotional entanglement between the three of us. Artistic style of animation works while the pursuit of strong personality style and unconventional design idea and the way of production, but they are in the animation art form, the audience's perception of exploration and experiment has played a guiding role.

Seven, as is known to all, in the eighty s, even in the ninety s, the two-dimensional animation was all the rage, occupies a large number of television channels and broadcast time, the animated cartoon "Mickey Mouse and Donald Duck", "Jimmy and jerry") and other commercial animation almost become a sign of public entertainment, they are all kinds of household image, and derived a lot of cultural products. But along with the advance of technology, the three dimensional animation, 
with its incomparable advantage began to disrupt the original pattern of animation, it is on the vision more expressive and impact, and closely integrated with the film, to adhere to the market and the culture of magic, won the unlimited business opportunities and development.

Space. Professor chau on wah in his "several trends in the development of contemporary western cartoon" the article pointed out that: "the three dimensional animation has been widely recognized, by simulation with computer graphics, image study and learn as a special shape, texture, texture, photosynthetic efficiency, etc., in the virtual world of images generated shows amazing special effects and three-dimensional conquer the animation industry is the main reason." Such as the 1995 pixar's "toy story" in the 77 - minute running time, with the 1561 full computer generated $3 \mathrm{~d}$ lens, with realistic scene, magnificent visual effect and difficult animation technology makes the three-dimensional images of the rage, for attention. According to the personage inside course of study, with the advent of the digital age, $3 \mathrm{~d}$ computer animation and special effects in movies using proportion is more and more big, especially the special effects for animation created a more broad space for development, it has become Canada's animation industry, and animation education the latest indicator. There are statistics show that provinces such as Ontario, Canada, the computer animation and special effects industry's annual earnings has amounted to \$200 million to \$1.7, computer animation production for 18000 to 21600 , the effects of content production annual output of 7400 to 9000 minutes. Computer animation company market earnings ratio is divided into: 16\% from animation film, $45 \%$ from TV animation, $17 \%$ from commercial advertising; Special effects to make the division of the company's earnings ratio is: $44 \%$ from movies, $16 \%$ from TV show, $13 \%$ from commercial advertising.

Therefore, animation, film and television animation series constitutes the mainstream in the development of animation industry. To that end, the government's response in a timely manner and quickly.

\section{References}

[1] Luo Zhe. Chinese Contemporary Animation Education Reflection .The Group Article Heaven and Earth [M]. 2011, we,

[2] Wu ChunYuan. Analysis China's Animation Education in Colleges and Universities. Intelligence 36, 2010.

[3]. Huang gang. the woods. The tutorial, Macromedia Flash MX standard Beijing hope electronic publishing house.

[4]. Huang Hanbin. Show good creative FLASH MX of bible teaching courseware and interactive games, people's posts and telecommunications publishing house

[5]. Kang Yu. Animation design training course, electronic publishing company

[6]. Turing. New Chinese FLASH MX tutorial [M] Shanghai: Shanghai Jiao Tong university press 